\title{
Hematuria as a Marker of Occult Urinary Tract Cancer: Advice for High-Value Care From the American College of Physicians
}

\author{
Matthew Nielsen, MD, MS, and Amir Qaseem, MD, PhD, for the High Value Care Task Force of the American College of \\ Physicians*
}

Background: The presence of blood in the urine, or hematuria, is a common finding in clinical practice and can sometimes be a sign of occult cancer. This article describes the clinical epidemiology of hematuria and the current state of practice and science in this context and provides suggestions for clinicians evaluating patients with hematuria.

Methods: A narrative review of available clinical guidelines and other relevant studies on the evaluation of hematuria was conducted, with particular emphasis on considerations for urologic referral.

High-Value Care Advice 1: Clinicians should include gross hematuria in their routine review of systems and specifically ask all patients with microscopic hematuria about any history of gross hematuria.

High-Value Care Advice 2: Clinicians should not use screening urinalysis for cancer detection in asymptomatic adults.

High-Value Care Advice 3: Clinicians should confirm hemepositive results of dipstick testing with microscopic urinalysis that demonstrates 3 or more erythrocytes per high-powered field before initiating further evaluation in all asymptomatic adults.

High-Value Care Advice 4: Clinicians should refer for further urologic evaluation in all adults with gross hematuria, even if self-limited.

High-Value Care Advice 5: Clinicians should consider urology referral for cystoscopy and imaging in adults with microscopically confirmed hematuria in the absence of some demonstrable benign cause.

High-Value Care Advice 6: Clinicians should pursue evaluation of hematuria even if the patient is receiving antiplatelet or anticoagulant therapy.

High-Value Care Advice 7: Clinicians should not obtain urinary cytology or other urine-based molecular markers for bladder cancer detection in the initial evaluation of hematuria.

Ann Intern Med. 2016;164:488-497. doi:10.7326/M15-1496 www.annals.org For author affiliations, see end of text.

This article was published at www.annals.org on 26 January 2016.
$\mathbf{H}$ ematuria is frequently encountered among adults in ambulatory care $(1,2)$. Despite the absence of recommendations for hematuria screening $(3,4)$, millions of patients have urine dipstick testing and microscopic examinations as part of routine primary care practice $(5,6)$. The frequency of urinalysis with the primary intent of cancer screening is unknown; however, hematuria may often be an incidental finding on tests pursued for other purposes, given the multiplex nature of dipstick tests. Referral series underscore the potential for a positive test result to be the presenting sign of occult cancer, and existing hematuria guidelines emphasize structured urologic investigation related to this risk with endoscopy of the bladder (cystoscopy), imaging, and potentially other diagnostic tests and procedures. However, the magnitude of the risk for underlying cancer varies greatly (7-9), and the quality of evidence informing practice creates uncertainty.

Hematuria occasionally has a dramatic presentation as grossly visible blood in the urine. Symptomatic gross hematuria with associated flank pain or renal

\section{See also:}

Summary for Patients. . . . . . . . . . . . . . . . . . I-34 colic is the classic presentation of urinary stone disease, whereas painless gross hematuria has a stronger association with cancer. Any episode of gross hematuria in an adult warrants consideration of urgent urologic evaluation, given the relatively high pretest probability of cancer or other clinically significant underlying conditions (consistently $>10 \%[7,8,10]$ and $>25 \%$ in some referral series [9]). Asymptomatic microscopic hematuria $(\mathrm{AMH})$ is more commonly encountered, with prevalence estimated at $0.9 \%$ to $18.0 \%$ in the adult population $(1,2)$. Patients referred for $\mathrm{AMH}$ have a relatively lower $(0.5 \%$ to $5.0 \%)$ but nontrivial probability of underlying occult cancer $(2,7-15)$ that is estimated to range from $7 \%$ to greater than $20 \%$ in higher-risk subgroups in some series $(9,16-18)$.

Against this backdrop, a review of current clinical practice suggests substantial unexplained variation in referral practices for patients with hematuria (8, 19-27), highlighting opportunities to increase awareness and define a high-value strategy to evaluate hematuria.

\section{MeTHODS}

We conducted a narrative literature review of published clinical guidelines that addressed the evaluation

\footnotetext{
* This paper, authored by Matthew Nielsen, MD, MS, and Amir Qaseem, MD, PhD, was developed for the High Value Care Task Force of the American College of Physicians (ACP). Individuals who served on the High Value Care Task Force from initiation of the project until its approval were Amir Qaseem, MD, PhD, MHA (Chair); John Biebelhausen, MD, MBA; Sanjay Desai, MD; Lawrence Feinberg, MD; Carrie A. Horwitch, MD, MPH; Linda L. Humphrey, MD, MPH; Robert M. McLean, MD; Tanveer P. Mir, MD; Darilyn V. Moyer, MD; Kelley M. Skeff, MD, PhD; Thomas G. Tape, MD; and Jeffrey Wiese, MD. Approved by the ACP Board of Regents on 27 April 2015.
} 


\begin{tabular}{|c|c|c|c|c|c|c|c|c|}
\hline \multirow[t]{2}{*}{ Recommendation } & \multirow[t]{2}{*}{ Year } & \multirow[t]{2}{*}{ Reference } & \multicolumn{4}{|c|}{ Case Definition } & \multicolumn{2}{|c|}{ Components of Evaluation } \\
\hline & & & Dipstick & $\begin{array}{l}\text { Microscopic } \\
\text { Urinalysis } \\
\text { Results, } \\
\text { erythrocytes/ } \\
\text { HPF }\end{array}$ & $\begin{array}{l}\text { Positive/ } \\
\text { Total } \\
\text { Test } \\
\text { Results, } \\
n / N\end{array}$ & $\begin{array}{l}\text { Age } \\
\text { Threshold, } \\
y\end{array}$ & Cystoscopy & $\begin{array}{l}\text { Preferred } \\
\text { Imaging Method }\end{array}$ \\
\hline $\begin{array}{l}\text { American Urological Association } \\
\text { guideline }\end{array}$ & 2012 & 12 & Inadequate & $\geq 3$ & 1 & $\geq 35$ & All patients & CT urography \\
\hline $\begin{array}{l}\text { American Urological Association } \\
\text { best practice policy }\end{array}$ & 2001 & 16 & Inadequate & $\geq 3$ & $2 / 3$ & $\geq 40$ & All patients & $\begin{array}{l}\text { CT urography or IVP/ } \\
\text { ultrasonography }\end{array}$ \\
\hline $\begin{array}{l}\text { Canadian Urological Association } \\
\text { guideline }\end{array}$ & 2008 & 30 & Inadequate & $\geq 2$ & 2 & $\geq 40$ & All patients & Renal ultrasonography \\
\hline $\begin{array}{l}\text { British Association of Urological } \\
\text { Surgeons guideline }\end{array}$ & 2008 & 32 & $\geq 1$ heme & Not required & $2 / 3$ & $\geq 40$ & Not specified & Not specified \\
\hline Dutch Guideline on Hematuria & 2010 & 31 & Inadequate & $\geq 3$ & $2 / 3$ & $\geq 50$ & All patients & Renal ultrasonography \\
\hline
\end{tabular}

$\mathrm{CT}$ = computed tomography; HPF = high-powered field; IVP = intravenous pyelography.

of hematuria as a marker of occult urinary tract cancer and other relevant studies from the peer-reviewed literature. This article was prepared with the intent to increase awareness and provide practical advice based on the best available evidence but was not based on a formal systematic review.

This article was reviewed and approved by the American College of Physicians' High Value Care Task Force, whose members are physicians trained in internal medicine and its subspecialties and which includes experts in evidence synthesis. The Task Force developed the high-value care advice statements based on the narrative review of the literature. At each conference call, all members of the High Value Care Task Force declared all financial and nonfinancial interests. The target audience for this article is all internists, family physicians, and other clinicians, and the target patient population is adults with hematuria. The purpose of this article is to describe indications for the evaluation of hematuria as a marker of occult urinary tract cancer and to help clinicians make high-value decisions about referral of patients for urologic assessment.

\section{What Are the Current Evidence-Based Guidelines for the ApPropriate Evaluation of Patients With Hematuria?}

Screening healthy, asymptomatic patients with urinalysis for the purpose of cancer detection is not currently recommended by any major health organization. This topic has been evaluated by the U.S. Preventive Services Task Force, which issued an "I" recommendation because of insufficient evidence on the benefits and harms (3). Neither the American Urological Association (AUA) nor the Canadian Task Force on the Periodic Health Examination recommends this practice (4, 12). A large case-control study of healthy adults receiving urinalysis as part of a health screening illustrates the limitations of population-based urinalysis screening, with no significant difference in incidence of cancer between those with and without dipstick-positive hematu- ria (screening had a sensitivity of $2.9 \%$ and a positive predictive value of $0.2 \%$ to $0.5 \%$ for cancer) (28).

Although little controversy surrounds the indication for urologic evaluation for patients with gross hematuria, the evaluation of patients with the more common finding of $\mathrm{AMH}$ is complicated by a lack of clarity about indications for referral and optimal components of the evaluation (Table 1). Many organizations have promulgated recommendations and algorithms relevant to the evaluation of patients with $\mathrm{AMH}$. In contrast to the AUA (29), the Canadian Urological Association (CUA) (30), and the Dutch guidelines (31), the British Association of Urological Surgeons (BAUS) specifically recommends evaluation based on a result of at least $1+$ heme on a chemical dipstick test and recommends against proceeding to confirmatory microscopy as an intermediate step (32). A microscopic examination of the urinary sediment from a freshly voided, clean-catch, midstream urine specimen is recommended to determine the presence of $\mathrm{AMH}$. The threshold of at least 3 erythrocytes per high-powered field (HPF) is consistent across most of the guidelines, and the requirement for microscopic confirmation in this context was selected by the AUA as a Choosing Wisely statement in 2015 (33). In a departure from the CUA and Dutch guidelines $(30,31)$ and the prior AUA best practice policy (16), which recommended microscopic confirmation on at least 2 of 3 specimens, the current AUA guideline suggests proceeding with evaluation on the basis of a single positive result on a microscopic analysis (12). This change was based on the literature that underscores the potential intermittent nature of hematuria from cancer $(14,15$, $17,18,34,35)$. Although limited, the literature that specifically examined different numerical thresholds for the number of erythrocytes per HPF found limited discrimination between incremental cut points, other than a threshold of at least 50 erythrocytes per HPF being associated with a significantly higher risk for cancer than a threshold of less than 50 erythrocytes per $\operatorname{HPF}(8,9)$. Whereas the AUA guidelines recommend evaluation for patients with $\mathrm{AMH}$ who are older than 35 years and 


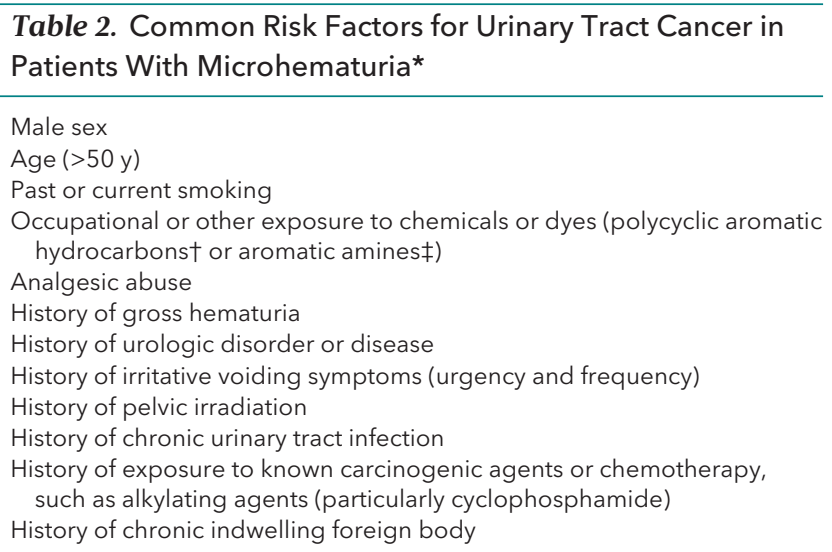

* Adapted from reference 29.

† Chimney sweeps; nurses; waiters; and aluminum, ship, and oil/petroleum workers (36).

$\ddagger$ Tobacco, dye, rubber, and leather workers; hairdressers; and printers (36).

patients of any age with risk factors for cancer (Table 2) $(29,36)$, the CUA and BAUS guidelines include 40 years or older as the age threshold $(30,32)$ and the Dutch guideline vignettes are framed around a cutoff of 50 years or older for the purposes of identifying the population at greatest risk (31). Recognizing age as a risk factor for cancer, the U.K. National Institute for Health and Clinical Excellence identified unexplained nonvisible hematuria in patients older than 60 years as a trigger for "suspected cancer pathway" referral for an appointment within 2 weeks (37).

The investigation of hematuria includes radiologic evaluation to identify potential pathology in the upper urinary tract. The American College of Radiology Appropriateness Criteria identified multiphase computed tomography (CT) urography as the preferred study in the evaluation of hematuria (38). The AUA recommends this method for all patients older than 35 years with at least 3 erythrocytes per HPF and no medical contraindications to intravenous contrast (12). The BAUS guideline (32) makes no specific recommendation about imaging method. The Dutch and CUA guidelines recommend ultrasonography as the first-line imaging method, with CT urography reserved for higher-risk cases and those with equivocal findings in the first-line evaluation. They both explicitly cite concerns related to radiation exposure and cost as the rationale for more selective use of CT imaging $(30,31)$. The AUA and BAUS guidelines recommend concurrent urologic evaluation in the presence of findings suggestive of potential nephrologic disorders (such as hypertension, renal insufficiency, cellular casts, proteinuria, or dysmorphic erythrocytes), whereas the CUA and Dutch guidelines suggest referral to a nephrologist as an alternative starting point in such cases.

The AUA guideline makes several salient points for clinicians to consider in the initial evaluation of $\mathrm{AMH}$ (29). It specifically notes that receipt of antiplatelet or anticoagulant therapy is not believed to be a satisfactory explanation for hematuria (39-41). Another important educational message for clinicians is that routine cytologic evaluation of urine is no longer recommended in the initial $\mathrm{AMH}$ evaluation, and urine markers approved by the U.S. Food and Drug Administration for bladder cancer detection (NMP22 BladderChek [Alere], BTA stat [Polymedco], ImmunoCyt [DiagnoCure], or UroVysion fluorescence in situ hybridization [Abbott Molecular]) are specifically not recommended for patients with $\mathrm{AMH}$ (12). This latter recommendation is consistent with the conclusions of a recent systematic review and meta-analysis of urinary biomarkers, which found that they miss a substantial proportion (18\% to $43 \%$ ) of patients with bladder cancer and give falsepositive results in $12 \%$ to $26 \%$ of patients without bladder cancer (42).

\section{What Harms Are Associated With the Evaluation OF HEMATURia?}

Harms associated with the diagnostic investigation of hematuria include the anxiety and discomfort associated with transurethral cystoscopy, which is routinely done under topical anesthesia (urethral lidocaine gel) with a flexible fiberoptic endoscope in the urology office. Complications of flexible cystoscopy are rare but can include urinary tract infection, sepsis, and urethral stricture (9). Estimates of the infection risk associated with cystoscopy vary by study population and definition of "infection," including positive result on urinalysis (5\% to $21 \%$ ) (43), bacteriuria (3\% to $9 \%$ ) (44), febrile urinary tract infection (1.4\% to $3.7 \%)(45)$, and symptomatic urinary tract infection $(0.85 \%)(46)$.

Harms associated with CT urography include nephropathy from intravenous contrast and the rare but real risk for life-threatening hypersensitivity reactions to contrast. Contrast nephropathy may occur in up to $2 \%$ of patients in the general population and at least $20 \%$ of high-risk patients with congestive heart failure, diabetes, or chronic kidney disease (47).

In addition, increasing attention is being paid to the potential longer-term harm of ionizing radiation exposure in the context of evidence linking doses in the range of multiphase CT scans to a significantly increased risk for cancer (48). The National Research Council concluded that patients exposed to as little as $10 \mathrm{mSv}$ may have increased risk for cancer (49). The median effective radiation dose associated with standard 3-phase CT urography has been estimated to be 20 to $30 \mathrm{mSv}$, depending on the scanner and imaging protocol (50-52), and concerns have been raised that the dose per examination has increased over the past decade (53). Evidence shows substantial variation in the effective radiation dose, with mean doses across facilities ranging from 24 to $45 \mathrm{mSv}$ and an absolute range of 6 to $90 \mathrm{mSv}$ for multiphase abdomen/pelvis CT in 1 contemporary multicenter study (54). Multiphase abdomen/pelvis CT has been associated with the highest effective dose and the highest adjusted lifetime attributable risk for cancer (4 cases per 1000 patients) among common CT protocols (54). Although radiation-associated cancer risk has traditionally been considered to decrease with age, recent evidence sug- 
gests that these risks may have a U-shaped distribution, with increasing risks after exposure in middle or older age (55). Despite the growing body of literature in this area, evidence shows limited awareness among clinicians of the radiation associated with $\mathrm{CT}$ imaging and its potential for carcinogenesis (56). Nevertheless, concern about radiation exposure is specifically articulated in several organizations' more selective recommendations for the use of CT imaging in evaluating hematuria $(30,31,57)$.

The downstream consequences, including costs, associated with the management of incidental findings of uncertain significance are other potential harms related to widespread CT imaging (58). Such findings may lead to potentially unnecessary anxiety, expenses, and physical risks associated with additional testing or procedures. Although limited data exist on the magnitude of such downstream consequences among patients being evaluated for hematuria (59), reports from the CT colonography literature highlight the potential extent of these issues in a screening population receiving anatomically similar imaging (60).

\section{What Are the Costs of Hematuria Evaluation?}

On both the individual and population levels, the costs associated with hematuria evaluation can be substantial. Table 3 presents the direct costs of tests recommended for the initial urologic evaluation of hematuria; these may vary on the basis of the practice setting (office- vs. hospital-based) (61-63). Even insured patients, an increasing proportion of whom are enrolled in high-deductible health plans, may have to bear a substantial proportion of these costs in copays and deductibles $(64,65)$. The costs of the consulting urologist's evaluation and management services are also a consideration, as well as any additional procedures or tests indicated in the adjudication of uncertain or suspicious findings on the initial evaluation. Although cytology still has a role for higher-risk patients with negative or equivocal initial evaluation results (29), indiscriminate use of these tests, as suggested in some earlier recommendations (66), could result in potentially substantial direct and indirect costs and unnecessary anxiety.

\section{What Is the Current State of Practice?}

Surveys of primary care physicians suggest that the use of urinalysis in adults in ambulatory care is common, with $44 \%$ to $77 \%$ of respondents in the past decade endorsing this as routine practice $(5,6,20)$. Although the motivation for urinalysis is not wellcharacterized, data from 1 serial survey suggest that its frequency has decreased (5). This study surveyed clinicians 5 times between 1978 and 2004 and found that their endorsement of routine urinalysis decreased from $93 \%$ to $44 \%$ based on a vignette describing a healthy 35 -year-old man and from $96 \%$ to $55 \%$ in a vignette of a healthy 55-year-old woman.

\begin{tabular}{|c|c|c|}
\hline Intervention & CPT Code & Reimbursement, \$ \\
\hline Microscopic urinalysis & 81015 & $4.14^{*}$ \\
\hline Cystoscopy & 52000 & $130.44 \dagger-548.93 \ddagger$ \\
\hline CT urography & 74170 and 72194 & $526.07 \dagger-612.43 \ddagger$ \\
\hline Urine cytology & 88112 & $65.04 \dagger$ \\
\hline Renal ultrasonography & 76770 & $114.63+-134.85 \ddagger$ \\
\hline
\end{tabular}

$\mathrm{CPT}=$ Current Procedural Terminology $; \mathrm{CT}=$ computed tomography . * 2015 national average payment amount from the Medicare fee-forservice Clinical Diagnostic Laboratory Fee Schedule (61).

† National facility prices from the Centers for Medicare \& Medicaid Services physician fee schedule based on the Medicare national average payment amount for 1 July to 31 December 2015 (62).

$\ddagger 2015$ Medicare national average outpatient hospital ambulatory patient classification payment (63).

When heme is detected on the chemical dipstick test, microscopic confirmation is required (12) because of the potential for false-positive results on up to one third of the tests, depending on the patient population $(67,68)$. Experience from urology practice supports the observation that a substantial number of $\mathrm{AMH}$ referrals may reflect an underappreciation of false-positive results, described as "dipstick pseudohematuria" (22). Although the magnitude of this problem is uncertain and may be below the $57 \%$ seen in the single study specifically examining it (22), clinical experience supports the need for increased awareness of the recommendation for confirmatory microscopy (33).

Although false-positive results on dipstick tests may lead to potentially avoidable referrals, there are also concerns in the urology community that limited awareness of the association between bona fide hematuria and potentially serious conditions may lead to delays in referral and timely diagnosis. A survey of primary care physicians from 2 U.S. metropolitan areas reported that $64 \%$ of microscopic hematuria findings were not routinely referred for urologic evaluation; potentially more concerning, given the substantially higher risk for underlying cancer associated with gross hematuria, $23 \%$ to $36 \%$ of respondents reported not routinely referring patients with that presentation (20).

Administrative data also suggest highly variable rates of urology referral after encounters with claims for hematuria diagnostic codes (from $4 \%$ to $47 \%)(19,21$, $23,25-27)$. Evidence suggests that this phenomenon occurs even among high-risk subgroups (Table 2), with a study of patients older than 50 years with a 10 -packyear or greater smoking history or 15-year or greater occupational exposure history finding referral rates of less than 15\% (24). Notwithstanding the limitations of these observational data, the apparent variability in referral rates and possible attendant delays in diagnosis raise concerns about potentially avoidable harms. For example, a study from the SEER (Surveillance, Epidemiology, and End Results)-Medicare data set found that patients with a delay greater than 9 months from the first claim for hematuria in the year before diagnosis of bladder cancer were more likely to die of the disease than those with an interval of 3 months or less (median cancer-specific survival of 50.9 months and 70.9 months, respectively [log-rank $P<0.001]$ ) (69). 
In addition, several studies have shown that, compared with men, women have substantially lower rates of urology referral ( $8 \%$ to $28 \%$ vs. $36 \%$ to $47 \%$ ), higher rates of incomplete diagnostic evaluations $(3.8 \%$ to $10.0 \%$ vs. $10.4 \%$ to $22.0 \%$ ), and longer delays to urology referral among patients with documented hematuria $(19,26,27)$. The reasons for these patterns of care are not clear from the available literature. Although men have a nearly 3-fold greater risk for bladder cancer, women typically present with more advanced disease and have a higher case-fatality rate (70), which raises the question of whether sex disparities in access may represent an opportunity for improvement.

\section{Why Does Practice Not Follow the EVIDENCE?}

The proportion of patients undergoing urinalysis with the intent of hematuria screening is unknown. To the extent that the motivation for urinalysis is multifactorial, the survey data cited previously suggest that its routine use has decreased in primary care practice in recent decades (5). Nevertheless, data suggest that a substantial proportion of patients continue to receive this testing. The utility of urinalysis that is primarily intended to screen for glycosuria or proteinuria, in which the detection of hematuria may be a finding incidental to the multiplex nature of the test, is beyond the scope of this review, but such testing in the general adult population does not seem to have high value (71, 72). Across the previously cited studies, a minority of patients with documented hematuria were referred for urologic evaluation for reasons that are not clear from the available data. Although it is acknowledged that a proportion of patients with $\mathrm{AMH}$ may have an identifiable benign cause in the initial evaluation, the level of detail in available data is inadequate to draw conclusions about the magnitude of potentially undesirable omission of referral.

\section{How Can Physicians Change Their Own Practice and Promote the Appropriate} Evaluation of Patients With Hematuria?

Routine urinalysis has questionable utility in asymptomatic patients, and screening healthy asymptomatic patients with the primary intent of cancer detection is not currently recommended by any major health organization. When dipstick urinalysis is done and results are positive for heme, practitioners should proceed to microscopic confirmation of erythrocytes in the urine before initiating referral. Although there may be local variation in laboratories' designated "normal range," a threshold of at least 3 erythrocytes per HPF is considered abnormal across several recommendations (Table 1). If menstruation, viral illness, vigorous exercise, or some other benign cause is suspected, the evaluation should be repeated after the cause is excluded. If infection is suspected based on urinalysis or symptoms, a urine culture should be obtained; if infection is con- firmed, the evaluation should be repeated after treatment to document resolution of hematuria. Because of the potential intermittent nature of hematuria, some organizations specifically recommend up to 3 repeated analyses in these scenarios (29). Given the potential burden of this recommendation and the limited evidence base supporting specific actions with respect to this practice, providers may consider repeated microscopic testing on the basis of the risk associated with the clinical presentation. Practitioners should be aware of risk factors for cancer (Table 2) when considering the finding of hematuria because data suggest that timely referral may be neglected, even in high-risk subgroups (24).

Increased awareness of the substantially stronger association of gross hematuria with cancer and other potentially serious underlying conditions is a key educational message for patients and practitioners (7-9). Although gross hematuria can be alarming, it is often self-limited, which could provide a false sense of security. This may explain, in part, why a substantial proportion of respondents in 1 primary care survey reported not referring patients with gross hematuria for urologic evaluation (20). Furthermore, emerging evidence suggests that a history of self-limited gross hematuria may be a common, important, and significantly underreported symptom. In a recent large prospective cohort study of patients referred to urologic evaluation for $\mathrm{AMH}, 19.8 \%$ reported visible hematuria in the preceding 6 months when they were specifically queried about this symptom (8). This was associated with an odds ratio of 7.2 for the presence of urologic cancer. The value of care in this setting may be substantially improved by providers reducing the indiscriminate use of urinalysis and specifically inquiring about a history of visible (or even self-limited) hematuria as part of their routine review of systems.

Increased awareness of current recommendations and components of the evaluation of patients with hematuria could also improve care delivery (Figure 1). Organizations may consider development of point-of-care educational tools, including decision-support interventions embedded in electronic medical records.

\section{Limitations OF THE EVIDENCE}

Although the literature suggests that office-based urinalysis is highly prevalent in primary care practice (5, $6,20)$, these data are from survey studies and have attendant limitations. The proportion of such tests that are primarily intended to screen for hematuria is unknown and may be small, given the multiplex nature of the test. Clinical experience in urology supports the observation of a potentially large number of inappropriate referrals for "dipstick pseudohematuria," which could subject many patients to a potentially avoidable cascade of anxiety, harms of invasive and radiographic testing, and costs (22); however, the findings of this small study have yet to be replicated. Although some clinical presentations of $\mathrm{AMH}$ (such as malignant hypertension, renal insufficiency, cellular casts, protein- 
Figure 1. Summary of recommendations for the evaluation of patients with hematuria.

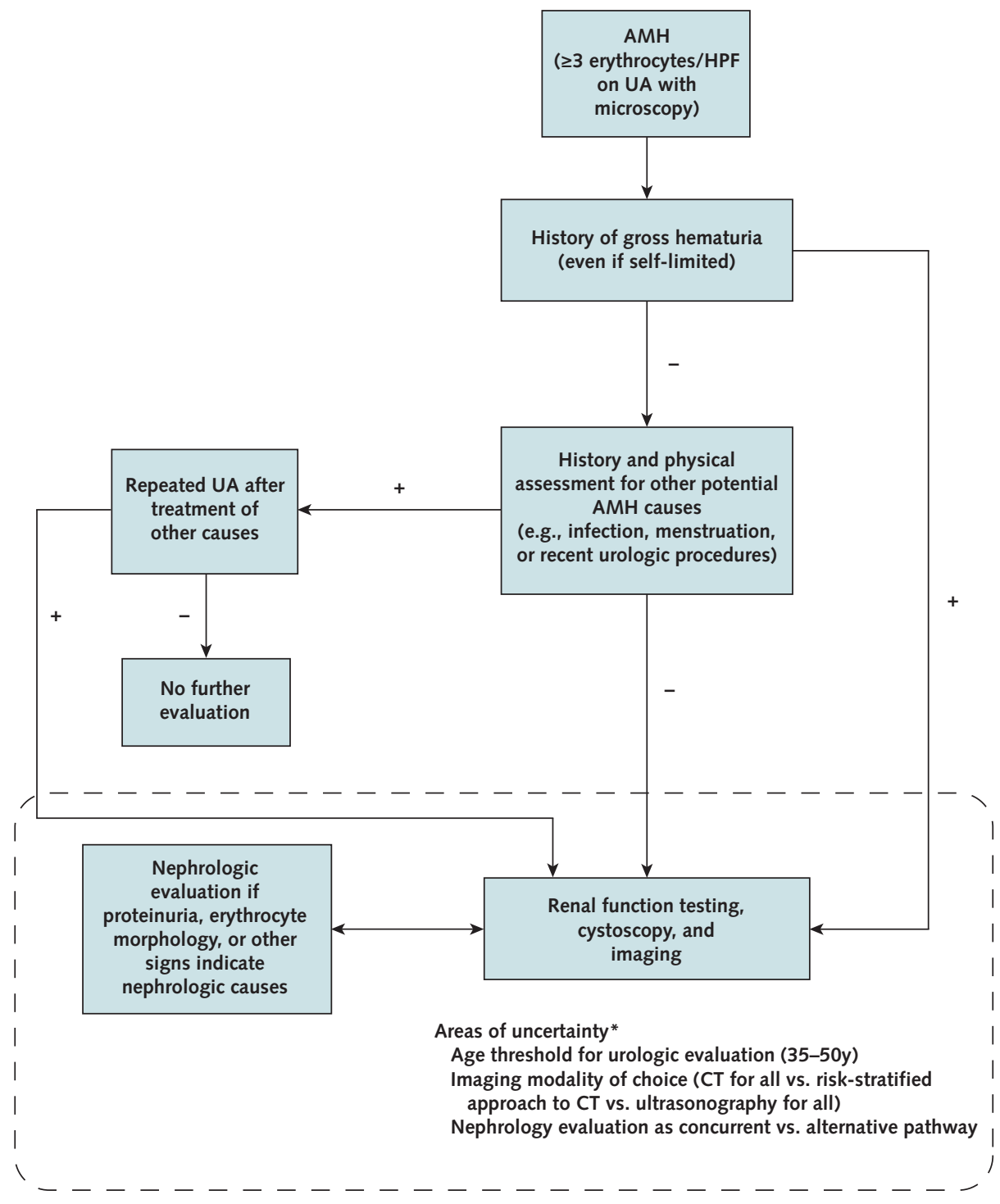

$\mathrm{AMH}=$ asymptomatic microscopic hematuria; $\mathrm{CT}=$ computed tomography; HPF = high-powered field; UA = urinalysis

* See Table 1 for more details.

uria, or dysmorphic erythrocytes) logically suggest diagnosis-directed management by a nephrologist as the appropriate first and potentially only consult, a detailed examination of current practice in that context was beyond the scope of this article. Although surveys and observational studies consistently show that a minority of patients with hematuria are referred, some degree of triage is expected; however, few data are available about the appropriateness of referral in practice.

Despite the prevalence of hematuria in routine practice and the economic and public health burden associated with identifying persons with potentially serious conditions, the quality of evidence to inform the execution of high-value care in this context is limited. The literature review for a formal health technology as-

www.annals.org sessment on this topic conducted by the U.K. National Institute for Health Research identified 79 hematuria diagnostic algorithms, none of which had been formally evaluated in terms of its effect on patient outcomes (73). The more recent evidence review informing the current AUA guideline reiterated this problem, with none of the specific recommendations therein supported by evidence with a grade higher than C (29). Differences among existing recommendations for the urologic evaluation of patients with $\mathrm{AMH}$ reflect value judgments in the context of substantial uncertainty inherent to the evidence base comprising observational studies of heterogeneous design. The concept of preference-sensitive guidelines (74) may be applicable to this context, and some physicians have advocated for the development of patient decision aids as a vehi- 
Figure 2. Summary of the American College of Physicians advice for high-value care on the evaluation of hematuria as a marker of occult urinary tract tumors.

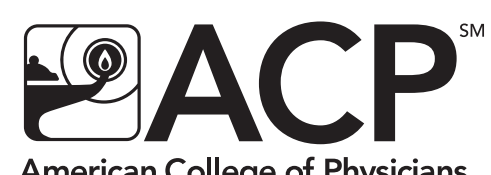

American College of Physicians

Leading Internal Medicine, Improving Lives

SUMMARY OF THE AMERICAN COLLEGE OF PHYSICIANS ADVICE FOR HIGH-VALUE CARE ON THE EVALUATION OF HEMATURIA AS A MARKER OF OCCULT URINARY TRACT CANCER

\begin{tabular}{|c|c|}
\hline Disease/Condition & Hematuria \\
\hline Target Audience & Internists, family physicians, and other clinicians \\
\hline Target Patient Population & Adults with hematuria \\
\hline Interventions Evaluated & $\begin{array}{l}\text { Urine dipstick testing } \\
\text { Microscopic urinalysis } \\
\text { Cystoscopy } \\
\text { Urinary cytology } \\
\text { Ultrasonography } \\
\text { Computed tomography }\end{array}$ \\
\hline Outcomes Evaluated & Cancer detection \\
\hline Benefits & Reduction in mortality and morbidity associated with possible cancer \\
\hline Harms & $\begin{array}{l}\text { Unnecessary testing } \\
\text { Complications related to cystoscopy (pain or infection) } \\
\text { Radiation exposure (for computed tomography) } \\
\text { Hypersensitivity reactions and contrast nephropathy (for iodinated contrast with computed tomography) } \\
\text { Potential association with subsequent unnecessary, invasive, and expensive procedures }\end{array}$ \\
\hline High-Value Care Advice & $\begin{array}{l}\text { High-Value Care Advice 1: Clinicians should include gross hematuria in their routine review of systems } \\
\text { and specifically ask all patients with microscopic hematuria about any history of gross hematuria. } \\
\text { High-Value Care Advice 2: Clinicians should not use screening urinalysis for cancer detection in } \\
\text { asymptomatic adults. } \\
\text { High-Value Care Advice 3: Clinicians should confirm heme-positive results of dipstick testing with } \\
\text { microscopic urinalysis that demonstrates } 3 \text { or more erythrocytes/HPF before initiating further } \\
\text { evaluation in all asymptomatic adults. } \\
\text { High-Value Care Advice 4: Clinicians should refer for further urologic evaluation in all adults with } \\
\text { gross hematuria, even if self-limited. } \\
\text { High-Value Care Advice 5: Clinicians should consider urology referral for cystoscopy and imaging } \\
\text { in adults with microscopically confirmed hematuria in the absence of some demonstrable benign cause. } \\
\text { High-Value Care Advice 6: Clinicians should pursue evaluation of hematuria even if the patient is } \\
\text { receiving antiplatelet or anticoagulant therapy. } \\
\text { High-Value Care Advice 7: Clinicians should not obtain urinary cytology or other urine-based molecular } \\
\text { markers for bladder cancer detection in the initial evaluation of hematuria. }\end{array}$ \\
\hline
\end{tabular}

HPF = high-powered field.

cle to promote shared decision making in the evaluation of $\mathrm{AMH}$ (75).

Two salient areas of discordance among existing $\mathrm{AMH}$ recommendations include the age threshold above which adults should be referred for urologic evaluation and the recommended method of upper urinary tract imaging (Table 1 ). These concepts have important implications for the value of care in this setting, framed by the heterogeneous pretest probabilities of $\mathrm{AMH}$ as a marker of serious diagnoses and, in turn, the question of whether a particular scheme of diagnostic 494 Annals of Internal Medicine • Vol. 164 No. 7 • 5 April 2016 testing in a given context provides health benefits that are worth the associated costs or harms (76). In particular, the nontrivial radiation exposure associated with CT urography may carry the greatest potential carcinogenesis risk in younger patients, among whom prior probability of $\mathrm{AMH}$ as a signal of occult upper urinary tract cancer is also the lowest $(7,8)$. Although the association between radiation exposure from CT imaging and lifetime cancer risk has been only indirectly estimated, the potential public health burden of harms of low-yield testing warrants further scrutiny. Against this 
backdrop, some organizations have implemented riskstratification algorithms that dramatically reduce the frequency of CT testing among the lower-risk subgroups of patients with hematuria (8).

\section{CONCLUSiON}

Health care practices associated with high costs, potentially avoidable harms, and limited or no benefits provide little value (76). The differing algorithms of existing recommendations for the evaluation of $\mathrm{AMH}$ reflect both current uncertainty in this area of practice and differences of opinion about the implicit tradeoffs among the harms, costs, and benefits of a given approach. These tradeoffs include both the threshold for initiating evaluation in a given case and the appropriate components of evaluation in a given circumstance ( $\mathrm{Ta}$ ble 1). Further research is needed to strengthen the evidence base supporting a high-value approach to the evaluation of the common finding of $\mathrm{AMH}$.

\section{High-Value Care Advice}

High-Value Care Advice 1: Clinicians should include gross hematuria in their routine review of systems and specifically ask all patients with microscopic hematuria about any history of gross hematuria.

High-Value Care Advice 2: Clinicians should not use screening urinalysis for cancer detection in asymptomatic adults.

High-Value Care Advice 3: Clinicians should confirm heme-positive results of dipstick testing with microscopic urinalysis that demonstrates 3 or more erythrocytes per high-powered field before initiating further evaluation in all asymptomatic adults.

High-Value Care Advice 4: Clinicians should refer for further urologic evaluation in all adults with gross hematuria, even if self-limited.

High-Value Care Advice 5: Clinicians should consider urology referral for cystoscopy and imaging in adults with microscopically confirmed hematuria in the absence of some demonstrable benign cause.

High-Value Care Advice 6: Clinicians should pursue evaluation of hematuria even if the patient is receiving antiplatelet or anticoagulant therapy.

High-Value Care Advice 7: Clinicians should not obtain urinary cytology or other urine-based molecular markers for bladder cancer detection in the initial evaluation of hematuria.

Figure 2 summarizes the advice and clinical considerations.

From University of North Carolina Lineberger Comprehensive Cancer Center, Chapel Hill, North Carolina, and American College of Physicians, Philadelphia, Pennsylvania.

Disclaimer: The authors of this article are responsible for its contents, including any clinical or treatment recommendations.

Financial Support: Financial support for the development of this article comes exclusively from the American College of
Physicians operating budget. Dr. Nielsen is supported by the American Cancer Society (grant MRSG-13-154-01-CPPB) and the Urology Care Foundation/Astellas (Rising Stars in Urology Research Award).

Disclosures: Dr. Nielsen reports personal fees from the American College of Physicians during the conduct of the study, other from Grand Rounds and Urology Care Foundation/Astellas outside the submitted work, and grants from the American Cancer Society and National Institutes of Health outside the submitted work. Authors not named here have disclosed no conflicts of interest. Forms can also be viewed at www .acponline.org/authors/icjme/ConflictOflnterestForms.do?ms Num=M15-1496. Authors followed the policy regarding conflicts of interest described at www.annals.org/article.aspx ?articleid $=745942$. A record of disclosures of interest is kept for each High Value Care Task Force meeting and conference call and can be viewed at http://hvc.acponline.org/clinrec .html.

Requests for Single Reprints: Amir Qaseem, MD, PhD, MHA American College of Physicians, $190 \mathrm{~N}$. Independence Mall West, Philadelphia, PA 19106; e-mail, aqaseem@acponline .org.

Current author addresses and author contributions are available at www.annals.org.

\section{References}

1. Mohr DN, Offord KP, Owen RA, Melton LJ 3rd. Asymptomatic microhematuria and urologic disease. A population-based study. JAMA. 1986;256:224-9. [PMID: 3723707]

2. Woolhandler S, Pels RJ, Bor DH, Himmelstein DU, Lawrence RS. Dipstick urinalysis screening of asymptomatic adults for urinary tract disorders. I. Hematuria and proteinuria. JAMA. 1989:262:1214-9. [PMID: 2668582]

3. Moyer VA; U.S. Preventive Services Task Force. Screening for bladder cancer: U.S. Preventive Services Task Force recommendation statement. Ann Intern Med. 2011;155:246-51. [PMID: 21844550] doi:10.7326/0003-4819-155-4-201108160-00008

4. Logsetty S. Screening for bladder cancer. In: Canadian Task Force on the Periodic Health Examination. Canadian Guide to Clinical Preventive Health Care. Ottawa, Ontario, Canada: Health Canada; 1994: 826-36.

5. Chacko KM, Feinberg LE. Laboratory screening at preventive health exams: trend of testing, 1978-2004. Am J Prev Med. 2007;32: 59-62. [PMID: 17218191]

6. Prochazka AV, Lundahl K, Pearson W, Oboler SK, Anderson RJ. Support of evidence-based guidelines for the annual physical examination: a survey of primary care providers. Arch Intern Med. 2005; 165:1347-52. [PMID: 15983282]

7. Edwards TJ, Dickinson AJ, Natale S, Gosling J, McGrath JS. A prospective analysis of the diagnostic yield resulting from the attendance of 4020 patients at a protocol-driven haematuria clinic. BJU Int. 2006;97:301-5. [PMID: 16430634]

8. Loo RK, Lieberman SF, Slezak JM, Landa HM, Mariani AJ, Nicolaisen G, et al. Stratifying risk of urinary tract malignant tumors in patients with asymptomatic microscopic hematuria. Mayo Clin Proc. 2013;88:129-38. [PMID: 23312369] doi:10.1016/j.mayocp.2012.10 .004

9. Mariani AJ, Mariani MC, Macchioni C, Stams UK, Hariharan A, Moriera A. The significance of adult hematuria: 1,000 hematuria evaluations including a risk-benefit and cost-effectiveness analysis. J Urol. 1989;141:350-5. [PMID: 2492350]

10. Khadra MH, Pickard RS, Charlton M, Powell PH, Neal DE. A prospective analysis of 1,930 patients with hematuria to evaluate current diagnostic practice. J Urol. 2000;163:524-7. [PMID: 10647670] 
11. Jung H, Gleason JM, Loo RK, Patel HS, Slezak JM, Jacobsen SJ. Association of hematuria on microscopic urinalysis and risk of urinary tract cancer. J Urol. 2011;185:1698-703. [PMID: 21419446] doi:10 .1016/j.juro.2010.12.093

12. Davis R, Jones JS, Barocas DA, Castle EP, Lang EK, Leveillee RJ, et al; American Urological Association. Diagnosis, evaluation and follow-up of asymptomatic microhematuria (AMH) in adults: AUA guideline. J Urol. 2012;188:2473-81. [PMID: 23098784] doi:10.1016/j .juro.2012.09.078

13. Mishriki SF, Nabi G, Cohen NP. Diagnosis of urologic malignancies in patients with asymptomatic dipstick hematuria: prospective study with 13 years' follow-up. Urology. 2008;71:13-6. [PMID: 18242356] doi:10.1016/j.urology.2007.08.031

14. Britton JP, Dowell AC, Whelan P. Dipstick haematuria and bladder cancer in men over 60: results of a community study. BMJ. 1989; 299:1010-2. [PMID: 2511941]

15. Britton JP, Dowell AC, Whelan P, Harris CM. A community study of bladder cancer screening by the detection of occult urinary bleeding. J Urol. 1992;148:788-90. [PMID: 1512826]

16. Grossfeld GD, Litwin MS, Wolf JS, Hricak H, Shuler CL, Agerter DC, et al. Evaluation of asymptomatic microscopic hematuria in adults: the American Urological Association best practice policypart I: definition, detection, prevalence, and etiology. Urology. 2001; 57:599-603. [PMID: 11306356]

17. Messing EM, Young TB, Hunt VB, Wehbie JM, Rust P. Urinary tract cancers found by homescreening with hematuria dipsticks in healthy men over 50 years of age. Cancer. 1989;64:2361-7. [PMID: 2804928]

18. Messing EM, Young TB, Hunt VB, Roecker EB, Vaillancourt AM, Hisgen WJ, et al. Home screening for hematuria: results of a multiclinic study. J Urol. 1992;148:289-92. [PMID: 1635120]

19. Bassett JC, Alvarez J, Koyama T, Resnick M, You C, Ni S, et al. Gender, race, and variation in the evaluation of microscopic hematuria among Medicare beneficiaries. J Gen Intern Med. 2015;30: 440-7. [PMID: 25451992] doi:10.1007/s11606-014-3116-2

20. Nieder AM, Lotan Y, Nuss GR, Langston JP, Vyas S, Manoharan $M$, et al. Are patients with hematuria appropriately referred to urology? A multi-institutional questionnaire based survey. Urol Oncol. 2010;28:500-3. [PMID: 19097811] doi:10.1016/j.urolonc.2008.10 .018

21. Buteau A, Seideman CA, Svatek RS, Youssef RF, Chakrabarti G, Reed G, et al. What is evaluation of hematuria by primary care physicians? Use of electronic medical records to assess practice patterns with intermediate follow-up. Urol Oncol. 2014;32:128-34. [PMID: 23153858] doi:10.1016/j.urolonc.2012.07.001

22. Rao PK, Gao T, Pohl M, Jones JS. Dipstick pseudohematuria: unnecessary consultation and evaluation. J Urol. 2010;183:560-4. [PMID: 20018314] doi:10.1016/j.juro.2009.10.049

23. Cohn JA, Vekhter B, Lyttle C, Steinberg GD, Large MC. Sex disparities in diagnosis of bladder cancer after initial presentation with hematuria: a nationwide claims-based investigation. Cancer. 2014; 120:555-61. [PMID: 24496869] doi:10.1002/cncr.28416

24. Elias K, Svatek RS, Gupta S, Ho R, Lotan Y. High-risk patients with hematuria are not evaluated according to guideline recommendations. Cancer. 2010;116:2954-9. [PMID: 20564400] doi:10.1002/cncr .25048

25. Friedlander DF, Resnick MJ, You C, Bassett J, Yarlagadda V, Penson DF, et al. Variation in the intensity of hematuria evaluation: a target for primary care quality improvement. Am J Med. 2014;127: 633-640.e11. [PMID: 24486290] doi:10.1016/j.amjmed.2014.01.010 26. Garg T, Pinheiro LC, Atoria CL, Donat SM, Weissman JS, Herr HW, et al. Gender disparities in hematuria evaluation and bladder cancer diagnosis: a population based analysis. J Urol. 2014;192: 1072-7. [PMID: 24835058] doi:10.1016/j.juro.2014.04.101

27. Johnson EK, Daignault S, Zhang Y, Lee CT. Patterns of hematuria referral to urologists: does a gender disparity exist? Urology. 2008; 72:498-502. [PMID: 18619657] doi:10.1016/j.urology.2008.01.086 28. Hiatt RA, Ordoñez JD. Dipstick urinalysis screening, asymptomatic microhematuria, and subsequent urological cancers in a population-based sample. Cancer Epidemiol Biomarkers Prev. 1994; 3:439-43. [PMID: 7848421]

29. Davis R, Jones JS, Barocas DA, Castle EP, Lang EK, Leveillee RJ, et al. Diagnosis, Evaluation and Follow-up of Asymptomatic Microhematuria (AMH) in Adults: AUA Guideline. Linthicum, MD: American Urological Association; 2012. Accessed at www.auanet.org /common/pdf/education/clinical-guidance/Asymptomatic-Micro hematuria.pdf on 30 September 2014.

30. Wollin T, Laroche B, Psooy K. Canadian guidelines for the management of asymptomatic microscopic hematuria in adults. Can Urol Assoc J. 2009;3:77-80. [PMID: 19293985]

31. van der Molen AJ, Hovius MC. Hematuria: a problem-based imaging algorithm illustrating the recent Dutch guidelines on hematuria. AJR Am J Roentgenol. 2012;198:1256-65. [PMID: 22623537] doi: 10.2214/AJR.11.8255

32. Fawcett D, Kelly J, Goldberg L, Anderson J, Feehally J, MacTier $\mathrm{R}$, on behalf of the Renal Association and British Association of Urological Surgeons. Joint Consensus Statement on the Initial Assessment of Haematuria. 2008. Accessed at www.renal.org/docs/default -source/what-we-do/RA-BAUS_Haematuria_Consensus_Guidelines .pdf?sfvrsn=0 on 21 December 2015.

33. American Urological Association. Choosing Wisely: Ten Things Physicians and Patients Should Question. Linthicum, MD: American Urological Association; 2015. Accessed at www.choosingwisely.org /societies/american-urological-association on 1 September 2015.

34. Messing EM, Young TB, Hunt VB, Emoto SE, Wehbie JM. The significance of asymptomatic microhematuria in men 50 or more years old: findings of a home screening study using urinary dipsticks. J Urol. 1987;137:919-22. [PMID: 2437335]

35. Messing EM, Young TB, Hunt VB, Newton MA, Bram LL, Vaillancourt $A$, et al. Hematuria home screening: repeat testing results. J Urol. 1995;154:57-61. [PMID: 7776456]

36. Cumberbatch MG, Cox A, Teare D, Catto JW. Contemporary occupational carcinogen exposure and bladder cancer: a systematic review and meta-analysis. JAMA Oncol. 2015:1-9. [PMID: 26448641] doi:10.1001/jamaoncol.2015.3209

37. National Institute for Health and Care Excellence. Suspected cancer: recognition and referral. NICE guideline. London: National Institute for Health and Care Excellence; 2015. Accessed at www .nice.org.uk/guidance/ng12/resources/suspected-cancer-recognition -and-referral-1837268071621 on 15 August 2015.

38. Shen L, Raman SS, Beland MD, Moreno CC, Goldfarb S, Harvin HJ, et al. ACR Appropriateness Criteria: Hematuria. 2014. Accessed at www.acr.org/ /media/ACR/Documents/AppCriteria/Diagnostic /Hematuria.pdf on 1 October 2014.

39. Culclasure TF, Bray VJ, Hasbargen JA. The significance of hematuria in the anticoagulated patient. Arch Intern Med. 1994;154:64952. [PMID: 8129498]

40. Van Savage JG, Fried FA. Anticoagulant associated hematuria: a prospective study. J Urol. 1995;153:1594-6. [PMID: 7536272]

41. Hurlen M, Eikvar L, Seljeflot I, Arnesen H. Occult bleeding in three different antithrombotic regimes after myocardial infarction. A WARIS-II subgroup analysis. Thromb Res. 2006;118:433-8. [PMID: 16139331]

42. Chou R, Gore JL, Buckley D, Fu R, Gustafson K, Griffin JC, et al. Urinary biomarkers for diagnosis of bladder cancer. A systematic review and meta-analysis. Ann Intern Med. 2015;163:922-31. doi:10 .7326/M15-0997

43. Rané A, Cahill D, Saleemi A, Montgomery B, Palfrey E. The issue of prophylactic antibiotics prior to flexible cystoscopy. Eur Urol. 2001;39:212-4. [PMID: 11223682]

44. Johnson MI, Merrilees D, Robson WA, Lennon T, Masters J, Orr $\mathrm{KE}$, et al. Oral ciprofloxacin or trimethoprim reduces bacteriuria after flexible cystoscopy. BJU Int. 2007;100:826-9. [PMID: 17822463] 45. Herr HW. The risk of urinary tract infection after flexible cystoscopy in patients with bladder tumor who did not receive prophylactic antibiotics. J Urol. 2015;193:548-51. [PMID: 25046618] doi:10 .1016/j.juro.2014.07.015 
46. Wilson L, Ryan J, Thelning C, Masters J, Tuckey J. Is antibiotic prophylaxis required for flexible cystoscopy? A truncated randomized double-blind controlled trial. J Endourol. 2005;19:1006-8. [PMID: 16253070]

47. Golshahi J, Nasri H, Gharipour M. Contrast-induced nephropathy; a literature review. J Nephropathol. 2014;3:51-6. [PMID: 24772397] doi:10.12860/jnp.2014.12

48. Brenner DJ, Hall EJ. Computed tomography-an increasing source of radiation exposure. N Engl J Med. 2007;357:2277-84. [PMID: 18046031]

49. Board on Radiation Effects Research, Division on Earth and Life Studies. Health Risks from Exposure to Low Levels of lonizing Radiation: BEIR VII Phase 2. Washington, DC: National Academies Pr; 2006.

50. Vrtiska TJ, Hartman RP, Kofler JM, Bruesewitz MR, King BF, McCollough $\mathrm{CH}$. Spatial resolution and radiation dose of a 64-MDCT scanner compared with published CT urography protocols. AJR Am J Roentgenol. 2009;192:941-8. [PMID: 19304698] doi:10.2214/AJR .07 .2679

51. Tsili AC, Efremidis SC, Kalef-Ezra J, Giannakis D, Alamanos $Y$, Sofikitis $\mathrm{N}$, et al. Multi-detector row CT urography on a 16-row CT scanner in the evaluation of urothelial tumors. Eur Radiol. 2007;17: 1046-54. [PMID: 17021709]

52. Mettler FA Jr, Huda W, Yoshizumi TT, Mahesh M. Effective doses in radiology and diagnostic nuclear medicine: a catalog. Radiology. 2008;248:254-63. [PMID: 18566177] doi:10.1148/radiol.2481071451 53. Smith-Bindman R, Miglioretti DL, Larson EB. Rising use of diagnostic medical imaging in a large integrated health system. Health Aff (Millwood). 2008;27:1491-502. [PMID: 18997204] doi:10.1377 /hlthaff.27.6.1491

54. Smith-Bindman R, Lipson J, Marcus R, Kim KP, Mahesh M, Gould $\mathrm{R}$, et al. Radiation dose associated with common computed tomography examinations and the associated lifetime attributable risk of cancer. Arch Intern Med. 2009;169:2078-86. [PMID: 20008690] doi: 10.1001/archinternmed.2009.427

55. Shuryak I, Sachs RK, Brenner DJ. Cancer risks after radiation exposure in middle age. J Natl Cancer Inst. 2010;102:1628-36. [PMID: 20975037] doi:10.1093/jnci/djq346

56. McBride JF, Wardrop RM 3rd, Paxton BE, Mandrekar J, Fletcher JG. Effect on examination ordering by physician attitude, common knowledge, and practice behavior regarding $\mathrm{CT}$ radiation exposure. Clin Imaging. 2012;36:455-461.e1. [PMID: 22920345] doi:10.1016/j .clinimag.2012.01.001

57. Loo R, Whittaker J, Rabrenivich V. National practice recommendations for hematuria: how to evaluate in the absence of strong evidence? Perm J. 2009;13:37-46. [PMID: 21373244]

58. Berland LL, Silverman SG, Gore RM, Mayo-Smith WW, Megibow AJ, Yee J, et al. Managing incidental findings on abdominal CT: white paper of the ACR incidental findings committee. J Am Coll Radiol. 2010;7:754-73. [PMID: 20889105] doi:10.1016/j.jacr.2010.06.013

59. Liu W, Mortelé KJ, Silverman SG. Incidental extraurinary findings at MDCT urography in patients with hematuria: prevalence and impact on imaging costs. AJR Am J Roentgenol. 2005;185:1051-6. [PMID: 16177432]

60. Berland LL. Incidental extracolonic findings on CT colonography: the impending deluge and its implications. J Am Coll Radiol. 2009; 6:14-20. [PMID: 19111266] doi:10.1016/j.jacr.2008.06.018
61. Centers for Medicare \& Medicaid Services. Clinical laboratory fee schedule. Baltimore: Centers for Medicare \& Medicaid Services; 2015. Accessed at www.cms.gov/Medicare/Medicare-Fee-for -Service-Payment/ClinicalLabFeeSched/clinlab.html on 3 September 2015.

62. Centers for Medicare \& Medicaid Services. Physician Fee Schedule Search. Baltimore: Centers for Medicare \& Medicaid Services; 2015. Accessed at www.cms.gov/apps/physician-fee-schedule/search /search-results.aspx?Y $=0 \& T=0 \& H T=0 \& C T=0 \& H 1=77263 \& M=5$ on 3 September 2015.

63. Centers for Medicare \& Medicaid Services. Hospital Outpatient PPS. Baltimore: Centers for Medicare \& Medicaid Services; 2015. Accessed at www.cms.gov/Medicare/Medicare-Fee-for-Service -Payment/HospitalOutpatientPPS/Hospital-Outpatient-Regulations -and-Notices-Items/CMS-1613-CN.html on 3 September 2015.

64. Kaiser Family Foundation; Health Research \& Educational Trust. Employer Health Benefits: 2014 Annual Survey. 2014. Accessed at http://files.kff.org/attachment/2014-employer-health-benefits-survey -full-report on 31 January 2015.

65. HealthPocket. Bronze Plan - Affordable Care Act (Obamacare). Accessed at www.healthpocket.com/individual-health-insurance /bronze-health-plans\#.VIXeMv8tDGg on 31 January 2015.

66. Cohen RA, Brown RS. Clinical practice. Microscopic hematuria. N Engl J Med. 2003;348:2330-8. [PMID: 12788998]

67. Grossfeld GD, Litwin MS, Wolf JS Jr, Hricak H, Shuler CL, Agerter DC, et al. Evaluation of asymptomatic microscopic hematuria in adults: the American Urological Association best practice policypart II: patient evaluation, cytology, voided markers, imaging, cystoscopy, nephrology evaluation, and follow-up. Urology. 2001;57:60410. [PMID: 11306357]

68. Corwin HL, Silverstein MD. Microscopic hematuria. Clin Lab Med. 1988;8:601-10. [PMID: 3139354]

69. Hollenbeck BK, Dunn RL, Ye Z, Hollingsworth JM, Skolarus TA, Kim SP, et al. Delays in diagnosis and bladder cancer mortality. Cancer. 2010;116:5235-42. [PMID: 20665490] doi:10.1002/cncr .25310

70. Mungan NA, Kiemeney LA, van Dijck JA, van der Poel HG, Witjes JA. Gender differences in stage distribution of bladder cancer. Urology. 2000;55:368-71. [PMID: 10699612]

71. Boulware LE, Jaar BG, Tarver-Carr ME, Brancati FL, Powe NR. Screening for proteinuria in U.S. adults: a cost-effectiveness analysis. JAMA. 2003;290:3101-14. [PMID: 14679273]

72. Friderichsen B, Maunsbach M. Glycosuric tests should not be employed in population screenings for NIDDM. J Public Health Med. 1997; 19:55-60. [PMID: 9138218]

73. Rodgers M, Nixon J, Hempel S, Aho T, Kelly J, Neal D, et al. Diagnostic tests and algorithms used in the investigation of haematuria: systematic reviews and economic evaluation. Health Technol Assess. 2006;10:iii-iv, xi-259. [PMID: 16729917]

74. Ubel PA. Medical facts versus value judgments-toward preference-sensitive guidelines. N Engl J Med. 2015;372:2475-7. [PMID: 26107051] doi:10.1056/NEJMp1504245

75. Hole B, Whittlestone T, Tomson C. Investigating asymptomatic invisible haematuria. BMJ. 2014;349:g6768. [PMID: 25404006] doi: 10.1136/bmj.g6768

76. Qaseem A, Alguire P, Dallas P, Feinberg LE, Fitzgerald FT, Horwitch $\mathrm{C}$, et al. Appropriate use of screening and diagnostic tests to foster high-value, cost-conscious care. Ann Intern Med. 2012;156: 147-9. [PMID: 22250146] doi:10.7326/0003-4819-156-2-201201170 $-00011$ 
Current Author Addresses: Dr. Nielsen: University of North Carolina Lineberger Comprehensive Cancer Center, 2107 Physicians Office Building, Campus Box 7235, Chapel Hill, NC 27599.

Dr. Qaseem: American College of Physicians, 190 N. Independence Mall West, Philadelphia, PA 19106.
Author Contributions: Conception and design: M. Nielsen, A. Qaseem.

Analysis and interpretation of the data: M. Nielsen, A. Qaseem.

Drafting of the article: M. Nielsen, A. Qaseem.

Critical revision of the article for important intellectual content: M. Nielsen, A. Qaseem.

Final approval of the article: M. Nielsen, A. Qaseem.

Statistical expertise: A. Qaseem.

Obtaining of funding: A. Qaseem.

Administrative, technical, or logistic support: A. Qaseem.

Collection and assembly of data: M. Nielsen. 